\title{
History and Progress of Fractional-Order Element Passive Emulators: A Review
}

\author{
Aslihan KARTCI ${ }^{1,2}$, Norbert HERENCSAR ${ }^{1}$, Jose Tenreiro MACHADO ${ }^{3}$, Lubomir BRANCIK ${ }^{4}$ \\ ${ }^{1}$ Dept. of Telecommunications, Brno University of Technology, Technicka 3082/12, 61600 Brno, Czech Republic \\ ${ }^{2}$ Computer, Electrical and Mathematical Sciences and Engineering Division, King Abdullah University of \\ Science and Technology, Thuwal 23955-6900, Saudi Arabia \\ ${ }^{3}$ Institute of Engineering, Polytechnic of Porto, Dept. of Electrical Engineering, Porto, Portugal \\ ${ }^{4}$ Dept. of Radio Electronics, Brno University of Technology, Technicka 3082/12, 61600 Brno, Czech Republic
}

$\{$ kartci, herencsn, brancik\}@feec.vutbr.cz, jtm@isep.ipp.pt

Submitted April 5, 2020 / Accepted April 19, 2020

\begin{abstract}
This paper presents a state-of-the-art survey in the area of fractional-order element passive emulators adopted in circuits and systems. An overview of the different approximations used to estimate the passive element values by means of rational functions is also discussed. A short comparison table highlights the significance of recent methodologies and their potential for further research. Moreover, the pros and cons in emulation of FOEs are analyzed.
\end{abstract}

\section{Keywords}

Circuit synthesis, constant phase element, fractional-order capacitor, fractional-order element, fractional-order emulator, $R C$ network, $R L$ network

\section{Introduction}

The term fractance or fractional-order capacitor (FOC), for an electrical element having properties between those of the resistance and capacitance, was suggested in 1983 by Alain Le Mehaute and Gilles Crepy for denoting electrical elements with non-integer order impedance [1]. In electrical engineering, the constant-phase behavior of capacitors is explained as the frequency dispersion of the capacitance due to the dielectric relaxation, where the electric current density follows the changes in the electric field with a delay. In 1994, Westerlund et al. [2] expressed this phenomenon in real capacitors, in the time domain as:

$$
D^{\alpha} v(t)=C^{-1} i(t)
$$

where $D^{\alpha} v(t)$ denotes the "fractional-order time derivative". In the same way, the given relationship for fractional-order inductor (FOI) is expressed as:

$$
I^{\alpha} v(t)=\operatorname{Li}(t)
$$

where $I^{\alpha} v(t)$ denotes the "fractional-order time integral" [3] with an order $0<\alpha<1$. Figure 1 shows these fundamental components in the frequency domain and possible fractional-order elements (FOEs) in the four quadrants of the complex plane [4]. Their impedance is described as $Z(s)=K s^{\alpha}$, where $\omega$ is the angular frequency with $s=\mathrm{j} \omega$ and the phase is given in radians $(\phi=\alpha \pi / 2)$ or in degrees $\left(\phi=90 \alpha^{\circ}\right)$. Obviously the impedance of the FOE has a real part dependent on the non-zero frequency and its magnitude varies by $20 \alpha \mathrm{dB}$ per decade of frequency. In particular, the impedance of Type IV FOEs, i.e. FOCs in quadrant IV, corresponds to an order $-1<\alpha<0$ and a pseudocapacitance $C_{\alpha}=1 / K$, whereas FOIs in quadrant I (Type I) have an order of $0<\alpha<1$ and a pseudoinductance of $L_{\alpha}=K$. Their units are expressed as farad $\cdot \sec ^{-\alpha-1}\left(\mathrm{~F} \cdot \mathrm{s}^{-\alpha-1}\right)$ and henry $\cdot \sec ^{\alpha-1}\left(\mathrm{H} \cdot \mathrm{s}^{\alpha-1}\right)$, respectively. Higher order FOCs and FOIs with the described impedances have frequency responses in quadrants II and III (Type II and III), respectively. Their characteristics such as the order $(\alpha)$, pseudocapacitance $\left(C_{\alpha}\right)$, pseudoinductance $\left(L_{\alpha}\right)$, constant phase zone $(\mathrm{CPZ})$,

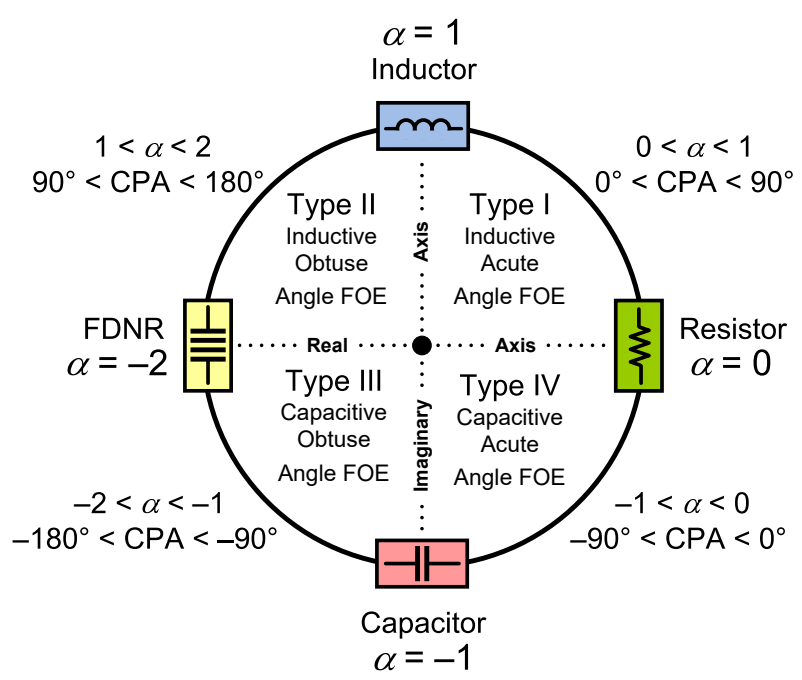

Fig. 1. Description of fractional-order elements in the four quadrants of the complex plane [4], [66]. 


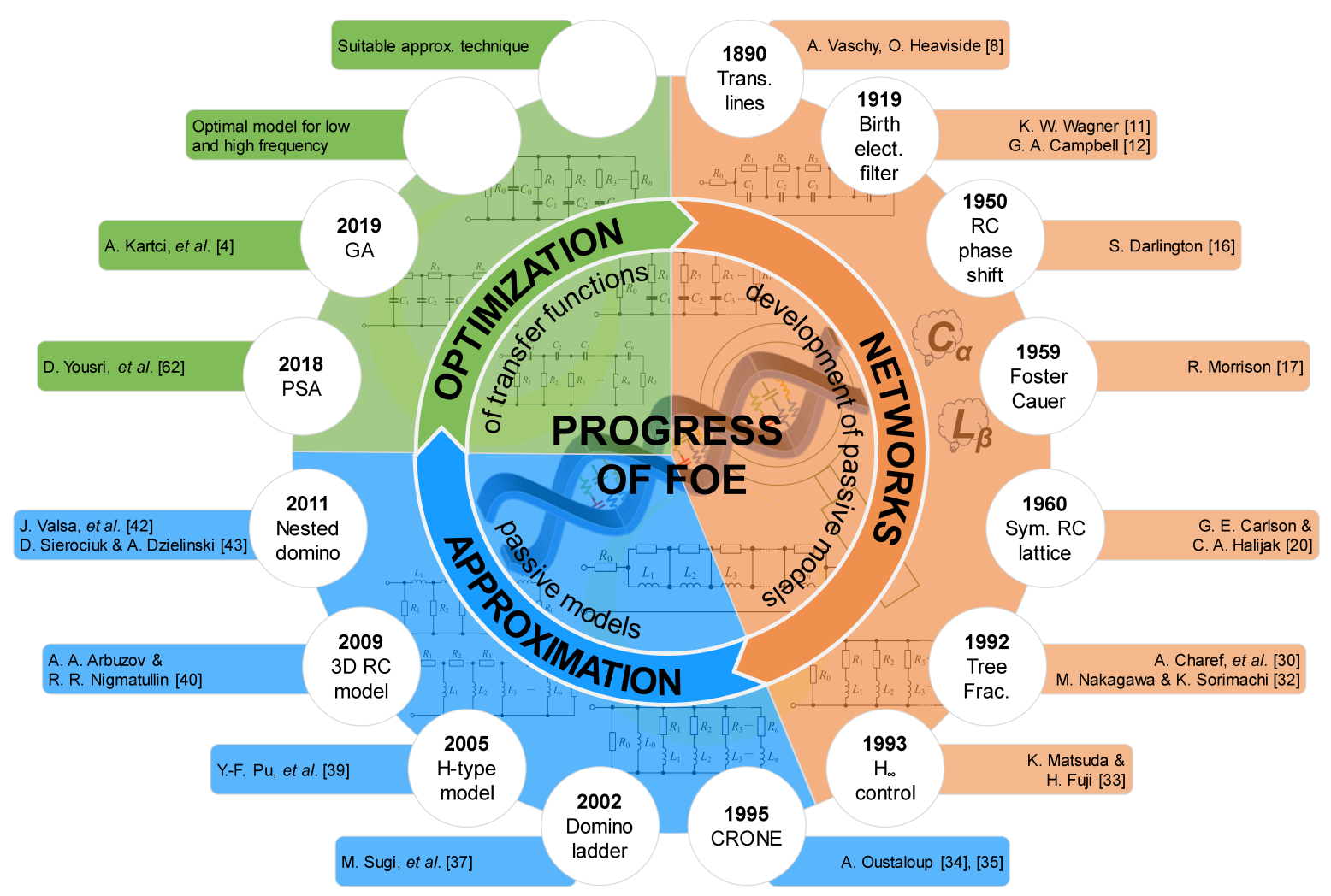

Fig. 2. Progress of fractional-order element emulators.

constant phase angle (CPA - defined phase angle in CPZ), phase angle deviation (PAD - maximum difference between a designed/measured phase and a target phase), or phase band (PB - difference between a designed/measured phase maximum and minimum phase deviation divided by two) influence significantly the transfer function of the fractional systems [5-7]. Therefore, in order to construct fractional operators, finite, infinite, semi-infinite dimensional integerorder systems resulting from the approximation of an irrational function can be used. Indeed, the nature of the fractional differ-integral does not allow the direct implementation in the time-domain simulations of systems with FOEs, while their mathematical representation in the frequency domain leads to irrational functions. Thus, in order to effectively analyze such systems, it is necessary to develop approximations to the fractional operators using standard integer-order operators. These integer-order transfer function approximations then can be used in the design of analog integrator and differentiator circuits by selecting the most adequate distribution of zeros and poles. This strategy makes the task of finding integer-order approximations of fractional transfer functions an important step. Therefore, when models are to be identified, or when simulations are to be performed, fractional transfer functions can be approximated by rational transfer functions, which are easier to handle. A variety of methods for the synthesis of passive FOCs have been proposed that differ from the approximation type. The implementations require standard capacitors and resistors, that are described by conventional (integer) models, but the circuit may include non-integer order elements. The realization of FOIs using resistive/inductive networks are limited due to their size, cost and limited operating frequency range. Therefore, the research on this area remained limited up to now [4]. In this work, an overview of passive FOE approximation techniques and emulators is provided highlighting the pros and cons of the alternative approaches pointing out the obstacles.

\section{Overview of Methods and Structures}

In the late 19th century, several researchers worked with the idea of improving the properties of long-distance transmission lines by inserting coils at regular intervals in these lines. Aime Vaschy and Oliver Heaviside were some of those pioneers [8]. The results were not overlooked at that time and no real progress was made until Mihajlo Idvorski Pupin [9] investigated the properties of the transmission cables. Adopting a combination of mathematical and experimental research, Pupin found that the damping in cables for telegraphy and telephony can be substantially reduced by judiciously inserting coils, which resulted in a widespread use of the so-called "Pupin lines". The properties of these lines were further investigated by George Ashley Campbell. In 1903, he published his findings [10] namely that they have a well-defined critical frequency that marks a sudden change in the damping characteristics. While Ashley was investi- 
gating these effects, Campbell pointed out that he used this effect to eliminate harmonics in signal generators. In fact, Campbell used the cable as a low-pass filter and moreover, he mentioned the possibility of using the cable as a bandpass filter by replacing the coils by combinations of coils and capacitors. In 1915, Karl Willy Wagner [11], from Germany, and G. A. Campbell, from USA [12], simulated independently the transmission-line by a ladder structure of impedances, mostly constructed as combinations of inductances and capacitances. This invention in 1915 is usually regarded as the birth of an electrical filter. The design theory of this type of filter bears the heritage from the transmissionline theory. Such filters were expressed in terms of characteristic impedances that should be matched if the stages cascaded. Later, from 1930 to 1940, Wilhelm Cauer [13] published a number of articles with the design of passive filters with transfer functions using Chebyshev approximations and having a given attenuation behavior. In 1939, Sidney Darlington [14] followed Cauer with the "insertion-loss theory". Unfortunately, these studies, as they were formulated, had few connection with real-world practice, which made them unpopular. Filters were implemented as networks of inductors, capacitors, and resistors. The problem of bulky and expensive inductors, with low quality factor, directed engineers to use the capacitors in many applications. Moreover, the filter transfer functions obtained with capacitive and resistive elements have their poles on the negative real axis of the Laplace plane. Complex poles are realizable, if active circuits are added. This gave rise to the use of active $R C$ filters [15].

In 1950, S. Darlington [16] proposed a compact form of transfer functions for determining the degree of approximation $(n)$ and for its analysis using pairs of capacitive-resistive phase-shifting networks. In this approach, each network is terminated with its own load along with $n$ all-pass sections. Each all-pass sections has the property of exhibiting identical ripple while the frequency range is determined between the lower and upper frequencies, respectively. Therefore, the CPZ is attributed to the phase shift network and is dependent on the complex nature of impedance. A theoretical study showed that the phase error and frequency range are inversely directly proportional to the degree of the approximation, respectively. The main problem of this approximation was the use of inductors and capacitors in all-pass sections, bringing difficulties of the practical circuit realization. In 1959, several networks with a parallel combination of a number of series infinite $R C$ elements to obtain a nearly pure constant argument (phase) over infinite frequency range were proposed by Ralph Morrison [17]. These networks have the basic canonic forms as Foster and Cauer. The constant phase behavior and the scaling factor were described mathematically and their relations were discussed over a two-decade frequency range. The effect of terminating (correcting, single, parallel connected) elements were given and a feedback amplifier design using a constant argument network was explained theoretically.
In 1961, Donald C. Douglas [18] introduced a design procedure to obtain a CPA with a phase from $-90^{\circ}$ to $+90^{\circ}$ with a predefined error in the specified frequency bandwidth. The phase error is independent from the network complexity, but that does not happen with the frequency range. The theory was based on Morrison's study and explained on a periodic rippling phase function by centering an infinite number of identical characteristics at identical intervals on a logarithmic frequency scale. For a phase angle of $45^{\circ}$, the error was $\pm 0.015^{\circ}$, while the error might vary for other phase angles. Setting the CPA with a given phase error and using simple schematics were the advantages of this method. However, special tables were required to attain the specified phase angle and error. This approach differed from the Morrison's method by the product of an infinite number of basic transfer functions (the Morrison's scheme was based on a summation of an infinite number of basic admittance functions). In 1963, Robert M. Lerner [19] proposed the finite network in which the poles and zeros of the string series of parallel $R L$ and $R C$ pairs were set according to the order $k$ whether equal to be positive or negative. The successive pairs of inductances and capacitances were set in the ratio of $p \in R^{+}$, and the resistors were in the ratio of $p^{k}$. Even though, similar structures were used as in the Morrison's study, Lerner took resistors with values following a power-law instead of $p$ as for the Morrison scheme, thereby reducing the repetitive errors in magnitude. In addition, the compensation impedance was specified to correct the edge ripples that could be modeled as the additional poles in the transfer function. An experimental admittance constructed with five capacitors and five resistors approximated a half-order impedance within the accuracy of $1 \%$ in magnitude and $\pm 1^{\circ}$ in phase over the frequency range of $50 \mathrm{~Hz}-10 \mathrm{kHz}$.

In 1964, Gordon E. Carlson and Charles A. Halijak [20] showed applications of a Newton process for approximating the characteristics of a balanced symmetric $R C$ lattice (cross $R C$ ladder). The networks were cascades of balanced symmetric lattices with unit resistors in the parallel arms and unit capacitors in the cross arms. The cascade was terminated with a unit resistor. This approximation involved highorder $\left(n^{\text {th }}\right)$ fractional capacitors whereas iterative methods were not common. The Newton process generated rational functions for the $n^{\text {th }}$ root of $1 / s$. Thus, a fractional capacitor of $n^{\text {th }}$ order was formally suggested and investigated the first time in the literature. Until 1967, only a few more studies were held. Kenneth Steiglitz [21] suggested a rational function approximation. Lerner employed a passive building block, and Cassius A. Hesselberth [22] investigated the lumped equivalent of Morrison's $R C$ circuits (Foster-type network). However, these networks were of theoretical interest only, because they were difficult to fabricate with the available technology.

In 1966, Suhash C. Dutta Roy [23] proposed the lumped element model of $R C$ networks with an impedance of $-45^{\circ}$ suitable for fabrication in micro-miniature form using thin 
film techniques. Later, he detailed this work [24] on nonuniform networks based on continued fraction expansion (CFE) and compared the results when adopting cascaded networks and rational function approximations. Moreover, the approximation $\left(1+s^{ \pm 1}\right)^{ \pm \lambda}$, where $\lambda$ is fractional-order and $-1 \leq \lambda \leq 1$, at low and high frequencies with suitable networks was discussed. Elliptic functions and an equiripple approximation were used. However, the approximations suffered from computational difficulties of the realization complexity.

In 1973, Keith B. Oldham [25] proposed a circuit having two stages, with the resistive-capacitive line subdivided into $n$-equal segments and having each segment replaced by a "T" element composed of two resistors and one capacitor. Then, the geometric ladder was generated by a similar two stage process, being only different from the initial subdivision into unequal segments. The proposed circuits could be adopted for any order, and the resistances and capacitances following a geometric progression leading, therefore, to much simpler calculations. Between 1975 and 1981 [26], six recursive arrangements of $R C$ or $R L$ cells (i.e., a parallel, series and cascade connection of $R C$ and $R L$ cells) were investigated, ensuring non-integer orders not limited to $1 / 2$, being possibly to vary between either 0 and 1 , or 0 and -1 .

In 1985 V. Ramachandran et al. [27], showed that an irrational immittance of the type $s^{1 / 2}$ could be realized exactly by a cascade connection of an infinite number of lumped symmetrical two-port networks. The transmission zeros of any two-port can be prespecified, provided they are not located on the negative real axis. Furthermore, the number of transmission zeros of any two-port can be predefined. It was shown that this approach gives a realization where the approximation of $s^{1 / 2}$ is possible over a large bandwidth.

By 1987 Jia-Chao Wang [28], based on some results of J. Schrama's thesis [29], proposed a systematic way to construct $R C$ transmission lines and ladder networks for producing generalized Warburg impedance. The specification of the starting points of the transmission lines was different the one adopted by Schrama. The main outcome was to show a non-constant resistance and capacitance per unit length of the line, while still referring the term "Warburg impedance".

In 1992, Abdelfatah Charef et al. [30], [31] proposed to approximate the fractional power pole. By using a simple graphical method, the zeros and the poles of the approximation for a specified error in $\mathrm{dB}$ were found to be in a geometric progression form, which is presently called "Charef's method". In the same year, Masahiro Nakagawa and Kazuyuki Sorimachi proposed a circuit having a fractal structure (tree fractance) composed of resistors and capacitors [32]. The impedance of the element described as $Z(\mathrm{j} \omega)=(R / C)^{1 / 2} \omega^{-1 / 2} \exp (\mathrm{j} \pi / 4)$ and the structure was used in fractional integral and differential circuits. In 1993, Khoichi Matsuda [33] presented a design broadband com- pensator following the $H_{\infty}$ control theory. In 1995, Alain Oustaloup [34], [35] developed the so-called Commande Robuste d'Ordre Non Entier (CRONE) suspension from the link between recursive and non-integer derivation. The noninteger derivation using $n$ elementary spring-damper cells with time constants distributed recursively, was synthesized based on a pre-defined frequency interval. However, the quality of the Oustaloup's approximation may not be satisfactory in the high and low frequency bands near the fitting frequency bounds. Moreover, it was restricted to odd orders. Later, this problem was solved by Dingyu Xue et al. in 2006 [36].

In 2002, Michio Sugi et al. [37] investigated self-similar ladder circuits with $R C$ elements (domino-type), forming a geometric progression for simulating fractional impedances of various orders. The claimed advantage with these selfsimilar circuits was the characterization of one single optimum pole interval determined by the distributed-relaxationtime models. Up to eighteen sections were used to realize an half-order element within bandwidth of a five decades. In 2005 [38], Yi-Fei Pu et al. [39] analyzed a tree-type network including half-order FOE resembling neural networks and proposed three half-order configurations net-grid type, two-circuit series, and $H$-type. In 2008, Andrey Arbuzov and Raoul R. Nigmatullin [40] presented three-dimensional selfsimilar $R C$ models of the electric double layer and electrolytic medium that gives fractional impedance response. The complex conductance of circuits are modeled by fractional-power expressions with real and complex-conjugated exponents. Moreover, it was shown that the fractional order was related to the dynamic fractal dimension, providing a geometrical meaning [41] to the concepts.

In 2011, Juraj Valsa et al. [42] proposed a systematic way to simulate the FOE in a desired frequency range for arbitrary orders. The parallel connection of the series of $R C$ elements was used with a parallel, a single resistor and a capacitor as correction elements. The approach was based on a recursive algorithm (RA) allowing the definition of the initial values from commercially available ones. Therefore, the remaining network values were close to the Electronic Industries Alliance (EIA) standard passive elements. By the same year, Dominik Sierociuk et al. [43], [44] introduced a new structure called the nested ladder. Together with the known domino structure, two types of electrical circuits provided the first known examples of circuits, made of passive elements only and exhibiting a behavior of variable order in the time/frequency domain. While the frequency dependent parameter was clear from the Bode plot, the variable order behavior of the circuits in the time domain was designed with help of Mittag-Leffler function as a link between data fitting and fractional-order differential equations [45]. In 2014, Reyad El-Khazali [46], [47] proposed a biquadratic approximation to fractional order differ-integral operators. The circuit was synthesized with series $R C$ and $R L$ networks. The performance of the structures showed better results than equiripple and Oustaloup's approximations, but the obtained passive values were not so realistic. 


\begin{tabular}{|c|c|c|c|c|c|c|c|}
\hline$C_{\mathrm{p}} / R_{\mathrm{p}}$ & $C_{1} / R_{1}$ & $C_{2} / R_{2}$ & $C_{3} / R_{3}$ & $C_{4} / R_{4}$ & $C_{5} / R_{5}$ & $C_{6} / R_{6}$ & $C_{7} / R_{7}$ \\
\hline $680 \mathrm{pF} / 240 \mathrm{k} \Omega$ & $820 \mathrm{nF} / 110 \mathrm{k} \Omega$ & $270 \mathrm{nF} / 39 \mathrm{k} \Omega$ & $91 \mathrm{nF} / 15 \mathrm{k} \Omega$ & $33 \mathrm{nF} / 5.1 \mathrm{k} \Omega$ & $11 \mathrm{nF} / 1.8 \mathrm{k} \Omega$ & $3.9 \mathrm{nF} / 680 \Omega$ & $1.6 \mathrm{nF} / 200 \Omega$ \\
\hline
\end{tabular}

Tab. 1. EIA standard E24 compliant $R C$ values for FOC of order -0.5 and $C_{\alpha_{-} \text {theor }}=3.75 \mu \mathrm{F} \cdot s^{-0.5}$ in CPZ from $1 \mathrm{~Hz}$ to $1 \mathrm{MHz}$ via the Valsa network.

In 2019, Avishek Adhikary et al. [48] proposed the design guidelines for Foster-type networks, so that a FOC can be realized with all specified parameters $\left(\alpha, C_{\alpha}\right.$, CPZ, CPA, and PAD/PB). The ladder FOC matches the specifications much closer than those obtained by other methods. However, the obtained passive values are still not EIA standard compliant.

Other structures validating the passive and active analog realizations of fractional-order impedances were proposed. We can mention composed of a FOC and some RLC components [49], active cells such as operational amplifiers, operational transconductance amplifiers, current conveyors, and current feedback operational amplifiers [50-52], and several others [53-58].

Evolutionary computing algorithms were used to reduce the drawbacks in optimization methods and to solve complex issues where conventional techniques fail. We find studies in different areas such as in control [59], [60] and chaos [61], or for extracting the design parameters of firstorder high-pass filters [62]. In this regard, we find genetic (GA), cuckoo search, and multi-verse algorithms, and as well as particle swarm, ant-lion, flower pollination, and whale optimizers [62-65]. In the proposed GA algorithm [4], instead of approximating $s^{\alpha}$ using the above approximations at a certain frequency (or bandwidth), a mixed integer-order GA was used for optimizing the phase and magnitude responses of the $R C / R L$ networks in the whole desired frequency range. The proposed GA takes into account all design parameters of the FOEs specified in [48]. However, no correction for using the commercially available $R C$ kit values is needed since the results obtained by the GA directly provides the EIA standard compliant component values as follows. Let us consider a study for comparing the performance of two different approaches. Therefore, for the $R C$ ladder-based FOC design the order $(\alpha=-0.5)$, pseudocapacitance $\left(C_{\alpha_{-} \text {theor }}=3.75 \mu \mathrm{F} \cdot s^{-0.5}\right)$, and CPZ $(1 \mathrm{~Hz}$ to $1 \mathrm{MHz})$ specifications are the same adopted in [48]. The $9^{\text {th }}$ order admittance function of Foster I [48], and the $8^{\text {th }}$ order admittance Valsa $R C$ function structures considered here are approximated. The distribution of resistance and capacitance values in the $R C$ networks required the FOCs listed in Tab. 1 of this paper and Tab. 5 of [48] are compared in Fig. 3. The passive elements are the EIA standard E24 compliant $R C$ values ( $5 \%$ tolerance) in both cases. We must note that some of the practical values listed in [48] are achieved by a series connection of two resistors or a parallel connection of two capacitors, which increases their complexity. Evaluating the practical values, the total capacitance of GA provided values is about $80 \%$ less, while the total resistance is nearly $15 \%$ greater than that listed in Tab. 5 of [48]. Figure 3 also indicates that the spread of the components is inferior for the GA

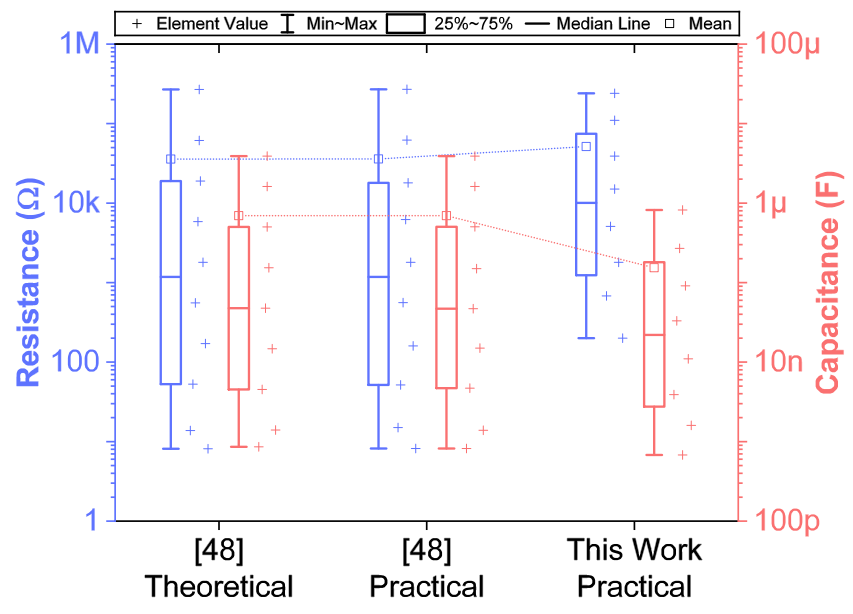

Fig. 3. Distribution of resistance and capacitance values in $R C$ networks realizing FOCs of orders -0.5 and $C_{\alpha_{-} \text {theor }}=3.75 \mu \mathrm{F} \cdot s^{-0.5}$ in CPZ from $1 \mathrm{~Hz}$ to $1 \mathrm{MHz}$.

\begin{tabular}{|c|c|c|c|}
\hline $\begin{array}{c}\text { Evaluation } \\
\text { criteria }\end{array}$ & $\begin{array}{l}\text { [48] Tab. } 5 \\
\text { Theoretical }\end{array}$ & $\begin{array}{c}\text { [48] Tab. } 5 \\
\text { Practical }\end{array}$ & $\begin{array}{c}\text { This Work } \\
\text { Practical }\end{array}$ \\
\hline Used $R C$ network & \multicolumn{2}{|c|}{ Foster I } & Valsa \\
\hline Order of approximation & \multicolumn{2}{|c|}{9} & 8 \\
\hline$\alpha_{\text {mean }}(-)$ & -0.5 & -0.5 & -0.5 \\
\hline$C_{\alpha \_ \text {mean }}\left(\mu \mathrm{F} \cdot s^{-\alpha-1}\right)$ & 3.86 & 3.87 & 3.80 \\
\hline & \multicolumn{3}{|c|}{$\mid$ Relative magnitude error $\mid(\%)$} \\
\hline$\overline{P A D}$ & 6.59 & 8.71 & 4.76 \\
\hline Mean & 3.01 & 3.59 & 1.59 \\
\hline Median & 2.95 & 3.28 & 1.42 \\
\hline \multirow[t]{2}{*}{ Standard Deviation } & 2.10 & 2.40 & 1.09 \\
\hline & \multicolumn{3}{|c|}{$\mid$ Phase angle error $\mid\left({ }^{\circ}\right)$} \\
\hline PAD & 3.47 & 3.20 & 1.51 \\
\hline Mean & 1.13 & 1.21 & 0.67 \\
\hline Median & 1.17 & 1.14 & 0.63 \\
\hline Standard Deviation & 0.63 & 0.78 & 0.42 \\
\hline
\end{tabular}

Tab. 2. Performance characteristics of FOCs of order -0.5 and $C_{\alpha_{-} \text {theor }}=3.75 \mu \mathrm{F} \cdot s^{-0.5}$ in $\mathrm{CPZ}$ from $1 \mathrm{~Hz}$ to $1 \mathrm{MHz}$.

\begin{tabular}{|c|c|c|c|}
\hline $\begin{array}{c}\text { Evaluation } \\
\text { criteria }\end{array}$ & $\begin{array}{c}\text { [48] Tab. 5 } \\
\text { Theoretical }\end{array}$ & $\begin{array}{c}\text { [48] Tab. 5 } \\
\text { Practical }\end{array}$ & $\begin{array}{c}\text { This Work } \\
\text { Practical }\end{array}$ \\
\hline RMSE $|Z|(\Omega)$ & 867.47 & 1034.85 & 602.12 \\
\hline RMSE $\phi\left(^{\circ}\right)$ & 1.29 & 1.44 & 0.79 \\
\hline
\end{tabular}

Tab. 3. Comparison of the Root Mean Square Errors of the proposed FOCs.

design due to limited range of the values in the population set according to the designer's choice. As a consequence, the mean of the GA values is slightly higher for $R$ and significantly lower for $C$ than those reported in [48]. The ideal and the simulated phase and magnitude responses vs. frequency of theoretical and practical FOCs are depicted in Fig. 4(a) and their performance is reported in Tab. 2. The mean of the fractional order is -0.5 for all realizations in defined CPZ, 


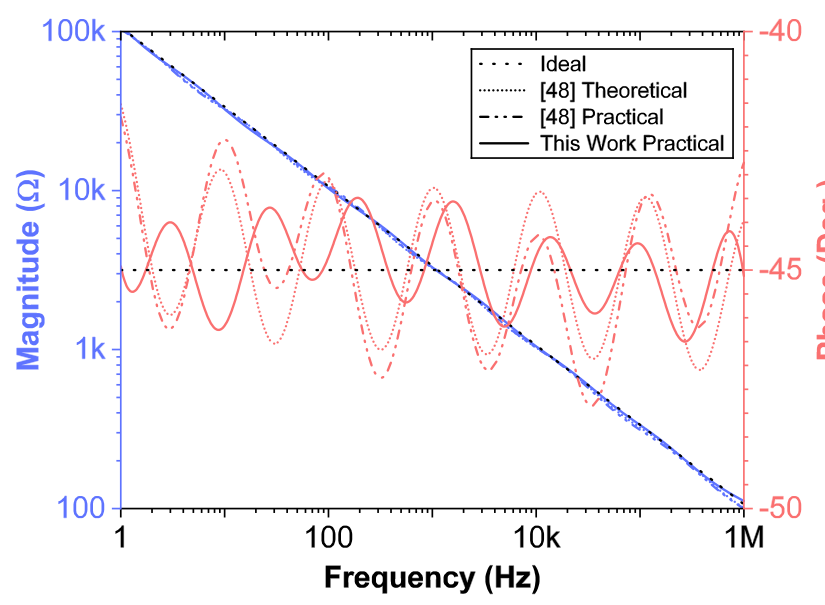

(a)

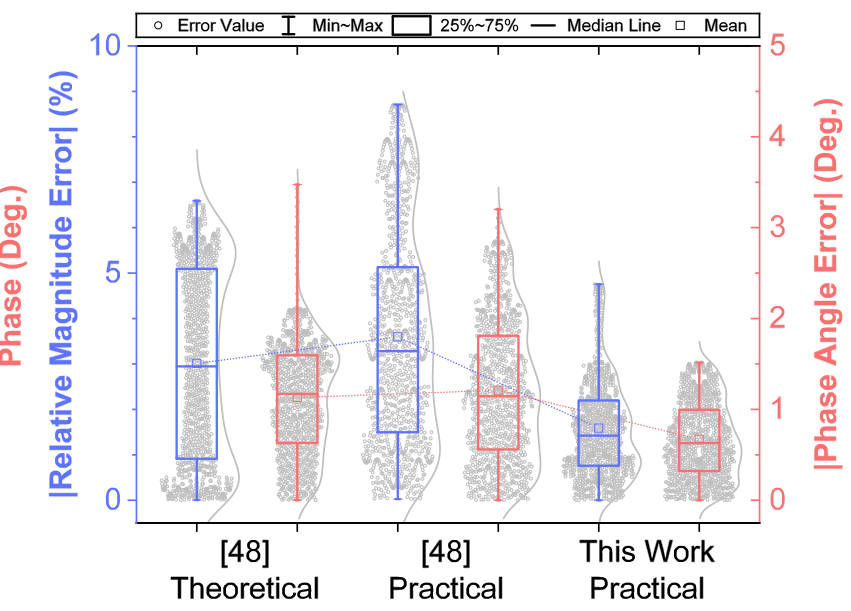

(b)

Fig. 4. (a) Ideal and simulated phase and magnitude responses vs. frequency, (b) distribution of absolute relative magnitude and phase angle errors of proposed FOCs of orders -0.5 .

while the mean of the pseudocapacitance is close to $C_{\alpha_{-} \text {theor }}$. Similarly, the relative magnitude and phase angle errors are the least for this work and their distribution is depicted in Fig. 4(b). The PB values for theoretical/practical [48] and this practical work are $2.78^{\circ} / 3.03^{\circ}$ and $1.51^{\circ}$, respectively. Moreover, the accuracy in magnitude and phase of the given FOC realizations, is assessed by means of standard Root Mean Square Error (RMSE). Table 3 again indicates, the GA provided FOC is more precise than the one in [48].

\section{Design Boundaries and Constrains}

In Sec. 2, various passive electrical networks were discussed for realizing fractional impedances. The irrational impedance is represented commonly in terms of a rational transfer function [6]. Therefore, to implement these functions and to obtain the values of the passive network component, we must have in mind several conditions:

- The transfer function must be real for the Laplace operator $s$.

- The transfer function has distinct features in the complex plane with negative real poles located in the open left-side of $s$-plane.

- The zeros of the input impedance $Z(s)$ pole or the input admittance $Y(s)$ zero should be the closest to the origin of the $s$-plane.

However, validating the conditions formulated above lead also to several drawbacks:

- The approximated rational functions require laborious calculations.

- The constrained optimization to identify the network.

- The passive component values are not optimally scaled and, therefore, negative values may be obtained, which requires the use of a negative impedance converter.

- The obtained values are not approximated close enough to standardized values, which leads to a poor approximation of the FOE.

- A high number of elements are used to reach a low phase error; hence, the FOE structures must have a large number of branches, that translates to high-order transfer functions.

- The high numbers of elements requires large circuit layouts that result in parasitic effects due to the transmission line particularly at high frequencies.

Therefore, a systematic design procedures should follow the guidelines:

- Use a suitable approximation technique to obtain the impedance in the form $Z(s)$ and to develop it into a suitable expansion.

- Use an appropriate network to reduce the phase ripple at low, mid, and high frequencies. Thus, the network should be selected according to the frequency range of the application.

- Use an evolutionary approximation technique to optimize the design specifications such as constant phase angle, order, pseudocapacitance/pseudoinductance value, phase ripple, constant phase zone, and predefined passive element values.

Fractional-order operations have been approximated also by algorithmic and computational procedures. Digital approximations are necessarily limited in bandwidth, require computer resources, and can suffer from numerical instabilities due to the finite precision arithmetic. These limitations can make digital techniques not the most adequate of solving some problems [49]. Therefore, this type of implementation strategy requires also considerable attention. 


\section{Conclusions}

The recent decades were marked by the development of FOEs and different models of fractal electrodes describing the processes in electrochemical cells. Various approaches to implement models were proposed and studied. However, many aspects are still far from being fully solved. Therefore, the literature survey made in this study help us to trace the chronological evolution of the concepts and approximations. The circuit network realization of FOEs having in mind an optimal design can benefit from artificial neural networks and nature inspired algorithms. The fractional-order, constant phase zone, pseudocapacitance or pseudoinducntance can be set by tuning the circuit parameters e.g., voltage, current, frequency. This can be done by using transistor-based active building blocks and with the conventional IC fabrication technologies. Therefore, this is still an open area and constitutes a promising field for future research.

\section{Acknowledgments}

This article is based upon work from COST Action CA15225, a network supported by COST (European Cooperation in Science and Technology). Research described in this paper was financed by the Ministry of Education, Youth and Sports under grant LTC18022 of Inter-Cost program.

\section{References}

[1] LE MEHAUTE, A., CREPY, G. Introduction to transfer and motion in fractal media: The geometry of kinetics. Solid State Ionics, 1983, vol. 9-10, p. 17-30. DOI: 10.1016/0167-2738(83)90207-2

[2] WESTERLUND, S., EKSTAM, L. Capacitor theory. IEEE Transactions on Dielectrics and Electrical Insulation, 1994, vol. 1, no. 5 , p. 826-839. DOI: 10.1109/94.326654

[3] MACHADO, J. A. T. Analysis and design of fractional-order digital control systems. Systems Analysis Modelling Simulation, 1997, vol. 27, no. 2-3, p. 107-122. ISSN: 0232-9298

[4] KARTCI, A., AGAMBAYEV, A., FARHAT, M., et al. Synthesis and optimization of fractional-order elements using a genetic algorithm. IEEE Access, 2019, vol. 7, p. 80233-80246. DOI: $10.1109 /$ ACCESS.2019.2923166

[5] ORTIGUEIRA, M. D. An introduction to the fractional continuoustime linear systems: The $21 \mathrm{st}$ century systems. IEEE Circuits and Systems Magazine, 2008, vol. 8, no. 3, p. 19-26. DOI: $10.1109 / \mathrm{MCAS} .2008 .928419$

[6] GIL'MUTDINOV, A. K., USHAKOV, P. A., EL-KHAZALI, R. Fractal Elements and Their Applications. Springer, 2017. ISBN: 978-3-319-45248-7. DOI: 10.1007/978-3-319-45249-4

[7] BISWAS, K., BOHANNAN, G., CAPONETTO, R., et al. FractionalOrder Devices. Springer, 2017. ISBN: 978-3-319-54459-5. DOI: 10.1007/978-3-319-54460-1

[8] VALÉRIO, D., MACHADO, J. T., KIRYAKOVA, V. Some pioneers of the applications of fractional calculus. Fractional Calculus and Applied Analysis, 2014, vol. 17, no. 2, p. 552-578. DOI: $10.2478 / \mathrm{s} 13540-014-0185-1$
[9] PUPIN, M. I. Wave transmission over non-uniform cables and long-distance air-lines. Transactions of the American Institute of Electrical Engineers, 1900, vol. XVII, p. 445-512. DOI: 10.1109/T-AIEE.1900.4764144

[10] CAMPBELL, G. A. On loaded lines in telephonic transmission. The London, Edinburgh, and Dublin Philosophical Magazine and Journal of Science, 1903, vol. 5, no. 27, p. 313-330. DOI: $10.1080 / 14786440309462928$

[11] WAGNER, K. W. Spulen- und Kondensatorleitungen. Electrical Engineering (Archiv fur Elektrotechnik), (in German), 1919, vol. 8, no. 2, p. 61-92. DOI: 10.1007/BF01597052

[12] CAMPBELL, G. A. Electric Wave-Filter. May 1917, US Patent $1,227,113$.

[13] CAUER, W. Siebschaltungen. V.D.I-Verlag, G.m.b.H., Berlin, (in German), 1931.

[14] DARLINGTON, S. Synthesis of reactance 4-poles which produce prescribed insertion loss characteristics: Including special applications to filter design. Journal of Mathematics and Physics, 1939, vol. 18 , no. $1-4$, p. $257-353$. DOI: $10.1002 /$ sapm 1939181257

[15] SALLEN, R. P., KEY, E. L. A practical method of designing RC active filters. IRE Transactions on Circuit Theory, 1955, vol. 2, no. 1, p. 74-85. DOI: 10.1109/TCT.1955.6500159

[16] DARLINGTON, S. Realization of a constant phase difference. The Bell System Technical Journal, 1950, vol. 29, no. 1, p. 94-104. DOI: 10.1002/j.1538-7305.1950.tb00934.x

[17] MORRISON, R. RC constant-argument driving-point admittances. IRE Transactions on Circuit Theory, 1959, vol. 6, no. 3, p. 310-317. DOI: 10.1109/TCT.1959.1086554

[18] DOUGLAS, D. C. A Method of Designing Constant-Phase Networks. Doctoral Thesis, Georgia Institute of Technology, 1961.

[19] LERNER, R. The design of a constant-angle or power-law magnitude impedance. IEEE Transactions on Circuit Theory, 1963, vol. 10, no. 1, p. 98-107. DOI: 10.1109/TCT.1963.1082094

[20] CARLSON, G. E., HALIJAK, C. A. Simulation of the Fractional Derivative Operator and the Fractional Integral Operator. Doctoral Thesis, Kansas State University, 1960.

[21] STEIGLITZ, K. An RC impedance approximant to $\mathrm{s}^{-1 / 2}$. IEEE Transactions on Circuit Theory, 1964, vol. 11, no. 1, p. 160-161. DOI: 10.1109/TCT.1964.1082252

[22] HESSELBERTH, C. A. Synthesis of Some Distributed RC Networks. Technical report, Coordinated Science Laboratory, University of Illinois at Urbana, 1963.

[23] ROY, S. D. On the realization of a constant-argument immittance or fractional operator. IEEE Transactions on Circuit Theory, 1967, vol. 14, no. 3, p. 264-274. DOI: 10.1109/TCT.1967.1082706

[24] ROY, S. C. D., SHENOI, B. A. Distributed and lumped $\mathrm{RC}$ realization of a constant argument impedance. Journal of the Franklin Institute, 1966, vol. 282, no. 5, p. 318-329. DOI: 10.1016/0016-0032(66)90260-2

[25] OLDHAM, K. B. Semiintegral electroanalysis. Analog implementation. Analytical Chemistry, 1973, vol. 45, no. 1, p. 39-47. DOI: $10.1021 / \mathrm{ac} 60323 \mathrm{a} 005$

[26] OUSTALOUP, A. Etude et Rèalisation d'un Système $d^{\prime}$ Asservissement d'Ordre $3 / 2$ de la Frèquence d'un Laser à Colorant Continu. Doctoral Thesis, Université Bordeaux I, France, (in French), 1975.

[27] RAMACHANDRAN, V., GARGOUR, C. S., AHMADI, M. Cascade realisation of the irrational immittance $\mathrm{s}^{1 / 2}$. IEE Proceedings $G$ Electronic Circuits and Systems, 1985, vol. 132, no. 2, p. 64-67. DOI: $10.1049 /$ ip-g-1.1985.0012 
[28] WANG, J. C. Realizations of generalized Warburg impedance with RC ladder networks and transmission lines. Journal of the Electrochemical Society, 1987, vol. 134, no. 8, p. 1915-1920. DOI: $10.1149 / 1.2100789$

[29] SCHRAMA, J. On the Phenomenological Theory of Linear Relaxation Processes. Doctoral Thesis, University of Leiden, Leiden, The Netherlands, 1957

[30] CHAREF, A., SUN, H. H., TSAO, Y. Y., et al. Fractal system as represented by singularity function. IEEE Transactions on automatic Control, 1992, vol. 37, no. 9, p. 1465-1470. DOI: 10.1109/9.159595

[31] SUN, H., CHAREF, A., TSAO, Y. Y., et al. Analysis of polarization dynamics by singularity decomposition method. Annals of Biomedical Engineering, 1992, vol. 20, no. 3, p. 321-335. DOI: $10.1007 / \mathrm{BF} 02368534$

[32] NAKAGAWA, M., SORIMACHI, K. Basic characteristics of a fractance device. IEICE Transactions on Fundamentals of Electronics, Communications and Computer Sciences, 1992, vol. 75, no. 12, p. 1814-1819. ISSN: 0916-8508

[33] MATSUDA, K., FUJII, H. $\mathrm{H}_{\infty}$ optimized wave-absorbing control -Analytical and experimental results. Journal of Guidance, Control, and Dynamics, 1993, vol. 16, no. 6, p. 1146-1153. DOI: $10.2514 / 3.21139$

[34] OUSTAlouP, A. La Dérivation non Entière: Theéorie, Synthèse et Applications. Hermes, (in French), 1995. ISBN: 978-2866014568

[35] OUSTALOUP, A., MOREAU, X., NOUILlANT, M. The CRONE suspension. Control Engineering Practice, 1996, vol. 4, no. 8 p. 1101-1108. DOI: 10.1016/0967-0661(96)00109-8

[36] XUE, D., ZHAO, C., CHEN, Y. A modified approximation method of fractional order system. In IEEE International Conference on Mechatronics and Automation. Luoyang, Henan (China), 2006, p. 1043-1048. DOI: 10.1109/ICMA.2006.257769

[37] SUGI, M., HIRANO, Y., MIURA, Y. F., et al. Frequency behavior of self-similar ladder circuits. Colloids and Surfaces A: Physicochemical and Engineering Aspects, 2002, vol. 198, p. 683-688. DOI: $10.1016 / \mathrm{S} 0927-7757(01) 00988-8$

[38] MACHADO, J., JESUS, I. Suggestion from the past? Fractional Calculus and Applied Analysis, 2004, vol. 7, no. 4, p. 403-407. ISSN: 1311-0454

[39] PU, Y.-F., YUAN, X., LIAO, K., et al. Structuring analog fractance circuit for $1 / 2$ order fractional calculus. In IEEE 6th International Conference on ASIC. Shanghai, 2005, p. 1136-1139. DOI: 10.1109/ICASIC.2005.1611507

[40] ARBUZOV, A. A., NigmatUllin, R. R. Three-dimensional fractal models of electrochemical processes. Russian Journal of Electrochemistry, 2009, vol. 45, no. 11, p. 1276-1286. DOI: $10.1134 / \mathrm{S} 1023193509110081$

[41] JESUS, I. S., MACHADO, J. A. T. Development of fractional order capacitors based on electrolyte processes. Nonlinear Dynamics, 2009, vol. 56, no. 1-2, p. 45-55. DOI: 10.1007/s11071-008-9377-8

[42] VALSA, J., DVORAK, P., FRIEDL, M. Network model of the CPE. Radioengineering, 2011, vol. 20, no. 3, p. 619-626. ISSN: 1210-2512

[43] SIEROCIUK, D., DZIELINSKI, A. New method of fractional order integrator analog modeling for orders 0.5 and 0.25 . In IEEE 16th International Conference on Methods \& Models in Automation \& Robotics (MMAR). Miedzyzdroje (Poland), 2011, p. 137-141. DOI: 10.1109/MMAR.2011.6031332

[44] SIEROCIUK, D., PODLUBNY, I., PETRAS, I. Experimental evidence of variable-order behavior of ladders and nested ladders. IEEE Transactions on Control Systems Technology, 2012, vol. 21, no. 2, p. 459-466. ISSN: 2374-0159. DOI: 10.1109/TCST.2012.2185932
[45] MACHADO, J. A. T., GALHANO, A. M. S. F. Fractional order inductive phenomena based on the skin effect. Nonlinear Dynamics, 2012, vol. 68 , no. 1-2, p. 107-115. DOI: 10.1007/s11071-011-0207-z

[46] EL-KHAZALI, R. Discretization of fractional-order differentiators and integrators. IFAC Proceedings Volumes, 2014, vol. 47, no. 3, p. 2016-2021. DOI: 10.3182/20140824-6-ZA-1003.01318

[47] EL-KHAZALI, R. On the biquadratic approximation of fractionalorder Laplacian operators. Analog Integrated Circuits and Signal Processing, 2015, vol. 82, no. 3, p. 503-517. DOI: $10.1007 / \mathrm{s} 10470-014-0432-8$

[48] ADHIKARY, A., SHIL, A., BISWAS, K. Realization of Foster structure-based ladder fractor with phase band specification. Circuits, Systems, and Signal Processing, 2020, vol. 39, no. 5, p. 2272-2292. DOI: $10.1007 / \mathrm{s} 00034-019-01269-\mathrm{w}$

[49] SARAFRAZ, M. S., TAVAZOEI, M. S. Realizability of fractionalorder impedances by passive electrical networks composed of a fractional capacitor and RLC components. IEEE Transactions on Circuits and Systems I: Regular Papers, 2015, vol. 62, no. 12, p. 2829-2835. DOI: 10.1109/TCSI.2015.2482340

[50] TSIRIMOKOU, G., PSYCHALINOS, C., ELWAKIL, A. S., et al. Experimental verification of on-chip CMOS fractional-order capacitor emulators. Electronics Letters, 2016, vol. 52, no. 15, p. 1298-1300. DOI: $10.1049 / \mathrm{el} .2016 .1457$

[51] TSIRIMOKOU, G., KARTCI, A., KOTON, J., et al. Comparative study of discrete component realizations of fractionalorder capacitor and inductor active emulators. Journal of Circuits, Systems and Computers, 2018, vol. 27, no. 11, p. 1850170. DOI: $10.1142 / \mathrm{S} 0218126618501700$

[52] SOTNER, R., JERABEK, J., PETRZELA, J., et al. Synthesis and design of constant phase elements based on the multiplication of electronically controllable bilinear immittances in practice. $A E U$ International Journal of Electronics and Communications, 2017, vol. 78, p. 98-113. DOI: 10.1016/j.aeue.2017.05.013

[53] CAPONETTO, R., PORTO, D. Analog implementation of non integer order integrator via field programmable analog array. IFAC Proceedings Volumes, 2006, vol. 39, no. 11, p. 107-111. DOI: 10.3182/20060719-3-PT-4902.00018

[54] IONESCU, C. M., MACHADO, J. A. T., DE KEYSER, R. Modeling of the lung impedance using a fractional-order ladder network with constant phase elements. IEEE Transactions on Biomedical Circuits and Systems, 2010, vol. 5, no. 1, p. 83-89. DOI: 10.1109/TBCAS.2010.2077636

[55] MA, Y., ZHOU, X., LI, B., et al. Fractional modeling and SOC estimation of lithium-ion battery. IEEE/CAA Journal of Automatica Sinica, 2016, vol. 3, no. 3, p. 281-287. DOI: 10.1109/JAS.2016.7508803

[56] PETRZELA, J. Accurate constant phase elements dedicated for audio signal processing. Applied Sciences, 2019, vol. 9, no. 22, p. 1-38. DOI: $10.3390 /$ app9224888

[57] SEMARY, M. S., FOUDA, M. E., HASSAN, H. N., et al. Realization of fractional-order capacitor based on passive symmetric network. Journal of Advanced Research, 2019, vol. 18, p. 147-159. DOI: 10.1016/j.jare.2019.02.004

[58] LIANG, G., HAO, J. Analysis and passive synthesis of immittance for fractional-order two-element-kind circuit. Circuits, Systems, and Signal Processing, 2019, vol. 38, no. 8, p. 3661-3681. DOI: 10.1007/s00034-019-01035-y

[59] SOLTEIRO PIRES, E. J., MACHADO, J. A. T. DE MOURA OLIVEIRA, P. B., et al. Particle swarm optimization with fractional-order velocity. Nonlinear Dynamics, 2010, vol. 61, no. 1, p. 295-301. DOI: 10.1007/s11071-009-9649-y 
[60] MACHADO, J. A. T. Optimal tuning of fractional controllers using genetic algorithms. Nonlinear Dynamics, 2010, vol. 62, no. 1-2, p. 447-452. DOI: $10.1007 / \mathrm{s} 11071-010-9731-5$

[61] DU, W., TONG, L., TANG, Y. Metaheuristic optimization-based identification of fractional-order systems under stable distribution noises. Physics Letters A, 2018, vol. 382, no. 34, p. 2313-2320. DOI: $10.1016 /$ j.physleta.2018.05.043

[62] YOUSRI, D., ABDELATY, A. M., RADWAN, A. G., et al. Comprehensive comparison based on meta-heuristic algorithms for approximation of the fractional-order Laplacian $\mathrm{s}^{\alpha}$ as a weighted sum of first-order high-pass filters. Microelectronics Journal, 2019, vol. 87, p. 110-120. DOI: 10.1016/j.mejo.2019.03.012

[63] CHU, P. C., BEASLEY, J. E. A genetic algorithm for the generalised assignment problem. Computers \& Operations Research, 1997, vol. 24, no. 1, p. 17-23. DOI: 10.1016/S0305-0548(96)00032-9

[64] SHI, Y., EBERHART, R. A modified particle swarm optimizer. In Proceedings of the IEEE International Conference on Evolutionary Computation Proceedings. IEEE World Congress on Computational Intelligence (Cat. No.98TH8360). Anchorage (USA), 1998, p. 69-73. DOI: $10.1109 /$ ICEC.1998.699146

[65] MACHADO, J. A. T., GAlHANO, A. M., OLIVEIRA, A. M., et al. Optimal approximation of fractional derivatives through discrete-time fractions using genetic algorithms. Communications in Nonlinear Science and Numerical Simulation, 2010, vol. 15, no. 3, p. 482-490. DOI: 10.1016/j.cnsns.2009.04.030

[66] KARTCI, A. Analog Implementation of Fractional-Order Elements and Their Applications. Doctoral Thesis, Brno University of Technology, Czechia, June 2019.

\section{About the Authors...}

Aslihan KARTCI received her Ph.D. degree in Electronics from Brno University of Technology, Czech Republic in 2019 and M.S. degree from Yildiz Technical University, Turkey, in 2015. Since January 2020, she has been with the King Abdullah University of Science and Technology (KAUST), Thuwal, Saudi Arabia, where she is a Postdoctoral Fellow of Sensors Lab., Computer, Electrical and Mathematical Science and Engineering Division and Advanced Membranes \& Porous Materials Center. Her research interests include fractional-order analog integrated circuits with modern active elements and their application as oscillators and filters, general element simulator, bio-impedance, bio-materials, energy storage devices.
Norbert HERENCSAR received the Ph.D. degree from the Brno University of Technology (BUT), Czech Republic, in 2010. In 2013 and 2014, he was a Visiting Researcher with the Bogazici University, Turkey, and also with the Dogus University, Turkey. In 2019, he was a Visiting Professor with the University of Calgary in Canada for six months. Since 2015, he has been an Associate Professor with the Dept. of Telecommunications, BUT. Since 2006, he has been collaborating on numerous research projects supported by the Czech Science Foundation. He is currently the Science Communications Manager and an MC Member of the COST Action CA15225 "Fractional-Order Systems-Analysis, Synthesis and Their Importance for Future Design". He has authored 90 articles published in SCI-E peer-reviewed journals and about 120 papers in conference proceedings. His research interests include analog electronics and fractional-order systems synthesis. Since 2011, he has been contributing as a Guest Co-Editor to several special journal issues in AEUInt. J. of Electron. and Commun., Radioengineering, and Telecommunication Systems. Since 2014, 2017, and 2018, he has been serving as an Associate Editor of the J. of Circuits, Systems and Computers (JCSC), IEEE Access, IEICE Electron. Express (ELEX), and an Editorial Board Member of the Radioengineering, Elektronika ir Elektrotechnika, and Fractal and Fractional, respectively. Since 2015, he has been serving in the IEEE Czechoslovakia Section Executive Committee as a SP/CAS/COM Joint Chapter Chair. He is a Senior Member of the IEEE.

José Tenreiro MACHADO was born at 1957, graduated with 'Licenciatura' (1980), Ph.D. (1989) and 'Habilitation' (1995) degrees in Electrical and Computer Engineering at the University of Porto. During 1980-1998 he worked as Professor at the Department of Electrical and Computer Engineering of the University of Porto. He is Principal Coordinator Professor at the Institute of Engineering, Polytechnic Institute of Porto, Dept. of Electrical Engineering.

Lubomir BRANCIK received the Ing. (MSc. equivalent) degree in Microelectronics and the CSc. (Ph.D. equivalent) degree in Measurements from the Brno University of Technology, Czech Republic, in 1985 and 1993, respectively, where he is currently a Professor of theoretical electrical engineering with the Department of Radio Electronics. From 2008 to 2010, he served as a Chair of the Czechoslovakia Section, IEEE. His research interests include numerical methods for the electrical engineering, computer-aided simulation, and signal integrity issues in electronic circuits. 